\section{Consumer Preferences for Geranium Flower Color, Leaf Variegation, and Price}

\author{
Bridget Behe $^{1}$ and Robert Nelson ${ }^{2}$ \\ Alabama Agricultural Experiment Station and Department of Horticulture, \\ Auburn University, AL 36849-5408 \\ Susan Barton ${ }^{3}$ \\ Department of Plant and Soil Science, University of Delaware, Newark, \\ DE 19717-1303
}

\section{Charles Hall ${ }^{4}$}

Department of Agricultural Economics, Texas A\&M University, College Station, TX 77843-2124

\section{Charles D. Safley ${ }^{5}$}

Department of Agricultural and Resource Economics, North Carolina State University, Raleigh, NC 27965-8109

\section{Steven Turner ${ }^{2}$}

Department of Agricultural and Applied Economics, University of Georgia, Athens, GA 30602-7509

Additional index words. marketing, conjoint analysis, consumer behavior, Pelargonium hortorum

\begin{abstract}
Researchers often investigate consumer preferences by examining variables consecutively, rather than simultaneously. Conjoint analysis facilitates simultaneous investigation of multiple variables. Cluster analysis facilitates development of actionable market segments. Our objective was to identify relative importance and consumer preferences for flower color, leaf variegation, and price of geraniums (Pelargonium xhortorum L.H. Bail.) and to identify several actionable market segments. We also evaluated the desirability of a hypothetical blue geranium. Photographic images were digitized and manipulated to produce plants similar in flower area, but varying in flower color (red, lavender, pink, white, and blue), leaf variegation (plain green, dark green zone, and white zone), and price (\$1.39 to \$2.79). Conjoint analysis revealed that flower color was the primary consideration in the purchase decision, followed by leaf variegation and price. A cluster analysis that excluded blue geraniums yielded four actionable consumer segments. When preferences for the blue geranium were included, six consumer segments were identified.
\end{abstract}

Consumers generally base their purchase decisions on several product characteristics, rather than just one. Thus, asking consumers how much they like one aspect of the product

Received for publication 22 May 1998. Accepted for publication 2 Oct. 1998. Journal No. 1-975875 of the Alabama Agricultural Experiment Station. The authors thank the Bedding Plants Foundation, Inc., for their generous financial support and Oglevee Associates for providing photographic images. This project was successfully completed as part of Regional Research Project S-103, "Technical Efficiencies in Horticulture Production and Marketing." The cost of publishing this paper was defrayed in part by the payment of page charges. Under postal regulations, this paper therefore must be hereby marked advertisement solely to indicate this fact. ${ }^{1}$ Associate Professor. Current address: Dept. of Horticulture, Michigan State Univ., East Lansing, MI 48824-1325; e-mail: behe@ @ilot.msu.edu

${ }^{2}$ Associate Professor.

${ }^{3}$ Extension Specialist.

${ }^{4}$ Associate Professor and Extension Specialist.

${ }^{5}$ Professor. (e.g., flower color) may not be the best indication of their overall preference for the product, or of the importance of a single factor in the market researchers to isolate a number of factors and determine the importance of each. Among applications in horticulture, this method has been used by Prince et al. (1980) with rose arrangements, Robertson and Chatfield (1982) with fresh flower bunches, Shafer and Kelly (1986) with potted chrysanthemums, Gineo (1990) with rhododendron sales to landscape contractors and retail garden centers, and Townsley-Brascamp et al. (1995) with outdoor ornamental plants.

Our objective was to identify consumer preferences for a variety of geranium flower colors, leaf variegations, and prices. This information was then used to: 1) estimate each consumer's utility for the five colors, three leaf types, and a range of prices; 2) calculate the relative importance of color, leaf, and price in the decision to buy; and 3) cluster the purchase decision. Conjoint analysis allows sample into consumer segments according to like preferences. A secondary objective was to test a novel method of predicting consumer response to a simulated product: a blue geranium. Oglevee Associates of Connelsville, $\mathrm{Pa}$., provided 35-mm negatives of four geranium cultivars. Digital-imaging technology was used to develop 25 test-pictures from photographs of red ('Sincerity'), lavender ('Danielle'), pink ('Ben Franklin'), and white ('Snowhite') geranium cultivars. A simulated light blue flower was created by digitizing the color onto the 'Snowhite' image. Leaf variegation included plain green leaf, dark zonal stripe on green leaf, and white margin on green leaf. Prices for geraniums (shown in 10-cmdiameter containers) were $\$ 1.39, \$ 1.59, \$ 1.99$, $\$ 2.39$, and $\$ 2.79$. These price points were selected to represent a low, moderate, and high price across the markets tested.

Because consumers would probably become fatigued if they were asked to rate all 75 combinations of flower color, leaf variegation, and price, we randomly generated an orthogonal array where participants would rate only 25 combinations. This fractionalfactorial design contained at least one occurrence of every color, leaf, and price, and from this we were able to infer information regarding all 75 possible combinations.

Photographs measuring $10 \mathrm{~cm} \times 15 \mathrm{~cm}$ were printed showing a single geranium plant with multiple flowers and leaves. Each photograph was mounted on a gray card for display, and a label showing the retail price was added to the lower left corner of the card. The 25 cards with photographs and prices were mounted on a display board in a random order. To reduce order bias, the cards were rearranged for each of the five market locations.

University researchers in five states (Alabama, Delaware, Georgia, North Carolina, and Texas) each recruited one traditional freestanding garden center cooperator to participate in the study. Customers over age 18 who were shopping in the garden center were asked to participate in the survey. Participants were asked to rate each of the 25 photographs on a scale from 1 ("definitely would NOT buy plant") to 5 ("definitely would buy plant"), and answer 10 additional questions relating to gardening and demographic characteristics. No incentive was used to improve response rate.

Respondents from the five stores returned 676 usable surveys. We compared consumer demographic characteristics and preferences by state, finding few differences (data not shown). Thus, we pooled all data for analyses. Analysis using Conjoint Analyzer software (Bretton-Clark, Morristown, N.J.) revealed that, for the overall sample of participants, flower color dominated the other two factors in importance, accounting for $52 \%$ of the buying decision (Table 1, last column). Leaf variegation ranked second, with $30 \%$ relative importance. Price was least important, with $18 \%$ relative importance. Overall, red and lavender were preferred over white and pink. For a given flower color, zonal and plain green leaves were preferred to leaves with white margins. As would be expected, lower prices 
were preferred to higher prices.

The potential for customer segmentation based on available geranium products (i.e., excluding the blue flower) was examined using cluster analysis (SAS Institute, 1998). Variables used for clustering were taken from the conjoint analysis for each respondent, and included the four coefficients for flower utility, the three coefficients for leaf utility, and the price vector. Clusters of size 2, 3, 4, 6, and 8 were examined using eight clustering algorithms. The four-cluster solution was selected for use in developing consumer market segment profiles because results showed peaks in the pseudo $t^{2}$ statistic for that solution in the majority of the eight methods tried.

A prominent segment of survey participants (32\% of the sample), referred to as the "Pink Lover" segment, strongly favored the pink color with the white leaf margin and was highly price-sensitive (Table 1). Among the demographic variables, "years gardening" was significantly different from the overall sample at $P \leq 0.10$. Another prominent segment in the four-cluster solution ( $31 \%$ of the sample) showed a preference for white flowers (and to a lesser extent, lavender flowers) with white leaf margins. These "White Lovers" were very sensitive to price and gave it the highest relative importance of any segment. This segment had no demographic variables that were significantly different from the overall sample $P \leq 0.10$.

A third segment, representing $21 \%$ of the sample, showed a strong preference for the archetypal geranium: red flower with green leaf. Among the four segments identified, the "Red Lovers" placed the highest relative importance on flower color, very low relative importance on leaf variegation, and little or none on price. They also had the highest average values for years gardening, age, education, family size, income, and proportion of men, although the last three were not significantly different from the overall sample means at the $P \leq 0.10$ level.

The last segment, the "Lavender Lovers," comprised $16 \%$ of the sample in this clustering solution. While they preferred lavender, they also liked red somewhat, and were slightly positive toward white. They preferred zonal and green leaves to the white leaf margin, and placed the highest relative importance of any segment on leaf variegation. Another way of characterizing these respondents would be to say they showed a strong dislike for pink flowers and white leaves, but this was not considered an actionable profile for targeting this segment. The Lavender Lovers was also the only segment that indicated a preference for higher prices (perhaps because respondents equated higher prices with higher-quality plants), and included the highest proportion of women in the sample.

The practical importance of these results is that flower color is by far the most important feature in purchasing geraniums (except for the Lavender Lover segment). In the overall sample, flower color was 1.7 times as important as leaf variegation and 2.9 times as important as price in the decision to buy. Also, a retail nursery may not need to stock all pos-

Table 1. Description of consumer segments derived from a four-cluster solution based on preferences for geranium attributes, excluding blue flower color.

\begin{tabular}{|c|c|c|c|c|c|}
\hline Variable & $\begin{array}{c}\text { Pink } \\
\text { Lovers }\end{array}$ & $\begin{array}{l}\text { White } \\
\text { Lovers }\end{array}$ & $\begin{array}{c}\text { Red } \\
\text { Lovers }\end{array}$ & $\begin{array}{c}\text { Lavender } \\
\text { Lovers }\end{array}$ & $\begin{array}{l}\text { Overall } \\
\text { sample }\end{array}$ \\
\hline $\mathrm{n}$ & 216 & 210 & 140 & 110 & 676 \\
\hline Percentage of sample & $32 \%$ & $31 \%$ & $21 \%$ & $16 \%$ & $100 \%$ \\
\hline \multicolumn{6}{|l|}{ Utility $^{\mathrm{z}}$ of: } \\
\hline PINKflower & $0.64^{*}$ & $-0.30^{*}$ & $-0.54^{*}$ & $-0.55^{*}$ & -0.09 \\
\hline WHITEflower & $-0.78^{*}$ & $0.41^{*}$ & -0.21 & $0.06^{*}$ & -0.16 \\
\hline REDflower & $0.09^{*}$ & $-0.25^{*}$ & $0.86^{*}$ & 0.14 & 0.15 \\
\hline LAVENDERflower & 0.05 & 0.14 & $-0.10^{*}$ & $0.35^{*}$ & 0.09 \\
\hline WHITEleaf & $0.17^{*}$ & $0.20^{*}$ & $-0.15^{*}$ & $-0.99^{*}$ & -0.08 \\
\hline ZONEleaf & $-0.07^{*}$ & $-0.10^{*}$ & 0.02 & $0.55^{*}$ & 0.04 \\
\hline GREENleaf & $-0.10^{*}$ & $-0.10^{*}$ & $0.12^{*}$ & $0.44^{*}$ & 0.03 \\
\hline PRICE & $-0.22^{*}$ & $-0.29^{*}$ & $-0.05^{*}$ & $0.14^{*}$ & -0.15 \\
\hline Percentage who bought in '95 & $56 \%$ & $62 \%$ & $64 \%$ & $57 \%$ & $60 \%$ \\
\hline No. plants bought in '96 & 4.0 & 4.7 & 3.9 & 5.4 & 4.4 \\
\hline Years gardening & $15.7^{*}$ & 17.3 & $19.1^{*}$ & 17.8 & 17.3 \\
\hline Size of garden $\left(\mathrm{m}^{2}\right)$ & 614 & 861 & 731 & 657 & 722 \\
\hline Age (years) & 43.9 & 43.5 & $46.0^{*}$ & 43.8 & 44.2 \\
\hline Gender (percent female) & $73 \%$ & $76 \%$ & $69 \%$ & $84 \% *$ & $75 \%$ \\
\hline Education (years) & 15.5 & 15.3 & $16.3^{*}$ & 15.3 & 15.6 \\
\hline Family size (persons) & 2.8 & 2.8 & 3.0 & 2.9 & 2.9 \\
\hline Income $(10=\$ 55-60 \mathrm{~K})$ & 9.7 & 9.4 & 10.1 & 10.0 & 9.7 \\
\hline Adjusted $R^{2}$ & 0.44 & $0.31^{*}$ & 0.45 & $0.51^{*}$ & 0.41 \\
\hline R.I. flower color ${ }^{\mathrm{y}}$ & $56 \% *$ & $49 \% *$ & $60 \% *$ & $39 \% *$ & $52 \%$ \\
\hline R.I. leaf variegation & $25 \% *$ & $29 \% *$ & $24 \% *$ & $47 \% *$ & $30 \%$ \\
\hline R.I. price & $18 \%$ & $22 \% *$ & $16 \% *$ & $15 \% *$ & $18 \%$ \\
\hline
\end{tabular}

${ }^{\bar{u}} \mathrm{u}=$ "Utility" of the variable, a more positive value being more desirable.

"R.I. = "Relative Importance" of the feature, a higher value indicating greater importance.

"Significantly different from overall sample at $P \leq 0.10$ by two-tail $t$ test.

Table 2. Description of consumer segments derived from a six-cluster solution based on preferences for geranium attributes, including blue flower color.

\begin{tabular}{|c|c|c|c|c|c|c|c|}
\hline Variable & $\begin{array}{c}\text { Pink } \\
\text { Lovers }\end{array}$ & $\begin{array}{l}\text { White } \\
\text { Lovers }\end{array}$ & $\begin{array}{c}\text { Red } \\
\text { Lovers }\end{array}$ & $\begin{array}{c}\text { Lavender } \\
\text { Lovers }\end{array}$ & $\begin{array}{c}\text { Blue } \\
\text { Lovers }\end{array}$ & $\begin{array}{c}\text { Question } \\
\text { Marks }\end{array}$ & $\begin{array}{l}\text { Overall } \\
\text { sample }\end{array}$ \\
\hline $\mathrm{n}$ & 88 & 92 & 106 & 163 & 161 & 66 & 676 \\
\hline Percentage of sample & $13 \%$ & $14 \%$ & $16 \%$ & $24 \%$ & $24 \%$ & $10 \%$ & $100 \%$ \\
\hline \multicolumn{8}{|l|}{ Utility $^{\mathrm{z}}$ of: } \\
\hline PINKflower & $0.98^{*}$ & $-0.81^{*}$ & $-0.17^{*}$ & 0.00 & 0.02 & $-0.40^{*}$ & -0.04 \\
\hline WHITEflower & $-0.68^{*}$ & $0.77^{*}$ & $0.44^{*}$ & $0.08^{*}$ & $-0.47^{*}$ & $-1.02^{*}$ & -0.11 \\
\hline REDflower & $0.51^{*}$ & $0.07^{*}$ & $0.94^{*}$ & $-0.05^{*}$ & $-0.34^{*}$ & $0.74^{*}$ & 0.20 \\
\hline LAVENDERflower & 0.14 & $-0.27^{*}$ & $0.55^{*}$ & $0.31^{*}$ & $-0.07^{*}$ & 0.15 & 0.14 \\
\hline BLUEflower & $-0.96^{*}$ & $0.24^{*}$ & $-1.77^{*}$ & $-0.34^{*}$ & $0.86^{*}$ & $0.53^{*}$ & -0.20 \\
\hline WHITEle: & $0.08^{*}$ & -0.17 & $-0.60^{*}$ & $-0.20^{*}$ & $0.40^{*}$ & $-0.20^{*}$ & -0.08 \\
\hline ZONEleaf & 0.04 & 0.10 & $0.32^{*}$ & $0.12^{*}$ & $-0.29^{*}$ & 0.06 & 0.03 \\
\hline GREENleaf & $-0.11^{*}$ & 0.06 & $0.28^{*}$ & 0.08 & $-0.11^{*}$ & $0.15^{*}$ & 0.05 \\
\hline PRICE vector (slope) & -0.21 & $-0.27^{*}$ & $0.02^{*}$ & -0.09 & $-0.27^{*}$ & $0.12^{*}$ & -0.14 \\
\hline ercentage who & $58 \%$ & $55 \%$ & $63 \%$ & $67 \%{ }^{*}$ & $53 \% *$ & $62 \%$ & $60 \%$ \\
\hline No. $\mathrm{pl}$ & 4.4 & 5.9 & $3.2^{*}$ & 5.5 & 3.7 & 3.5 & 4.4 \\
\hline Years & 16.0 & 16.1 & $20.1^{*}$ & 18.1 & $15.2^{*}$ & 18.8 & 17.2 \\
\hline Size of garden $\left(\mathrm{m}^{2}\right)$ & 550 & 890 & 769 & 743 & 653 & 755 & 722 \\
\hline Age (years) & 44.2 & 42.7 & 45.1 & 45.4 & $41.4^{*}$ & $48.3^{*}$ & 44.2 \\
\hline Gender (percent female) & $81 \%$ & $74 \%$ & $88 \%{ }^{*}$ & $74 \%$ & $73 \%$ & $55 \% *$ & $75 \%$ \\
\hline Education (years) & 16.0 & 15.8 & 16.0 & $15.1^{*}$ & 15.5 & 15.6 & 15.6 \\
\hline Famil & 2.8 & 2.7 & 2.9 & 2.8 & 2.9 & 3.1 & 2.9 \\
\hline Incor & 10.1 & 10.0 & 10.0 & 9.4 & 9.4 & 10.0 & 9.7 \\
\hline Adjuste & $0.61^{*}$ & 0.48 & $0.66^{*}$ & $0.29^{*}$ & 0.45 & $0.56^{*}$ & 0.48 \\
\hline R.I. flower $\mathrm{c}$ & $67 \% *$ & $59 \%$ & $67 \%^{*}$ & $52 \%^{*}$ & $55 \%{ }^{*}$ & $67 \%^{*}$ & $60 \%$ \\
\hline R.I. leaf variegation & $19 \%^{*}$ & $25 \%$ & $24 \%$ & $28 \%^{*}$ & $27 \%^{*}$ & $21 \%{ }^{*}$ & $25 \%$ \\
\hline R.I. price & $14 \%$ & $17 \%$ & $9 \% *$ & $20 \%{ }^{*}$ & $17 \%$ & $12 \%{ }^{*}$ & $15 \%$ \\
\hline
\end{tabular}

${ }^{\mathrm{z}} \mathrm{u}=$ "Utility" of the variable, where a more positive value is more desirable to the segment.

${ }^{y}$ R.I. = "Relative Importance" of the feature, where a higher value indicates greater importance to the segment.

${ }^{*}$ Significant at $P \leq 0.10$ (compared with overall sample in a two-tail $t$ test).

sible combinations of leaf variegation and flower color. Of the 12 possible combinations in this study, in only six did flower and leaf both contribute positively to the purchase decision. These were zonal and green leaves with red and lavender flowers, and the white-margin leaf with pink and white flowers. Finally, promotional pricing strategies could increase sales of pink and white geraniums, but would probably not be advisable for red, and certainly not for lavender, geraniums, since consumers in these segments would not be responsive to reduced price.

A separate cluster analysis was conducted 
using consumers' responses to combinations involving the simulated blue geranium (Table 2). A six-cluster solution was indicated by six of the eight clustering algorithms used. Of the six clusters, four were given the same names as those in the previous analysis, while the two new clusters were called the "Blue Lovers" cluster and the "Question Marks" cluster, so named because while the members favored red, blue, and lavender flowers, they were excluded from those specific segments for other reasons, probably strong preferences against the white flower and in favor of higher prices.

The proportion of the sample represented by each cluster changed considerably in response to the choice of a blue geranium. The clusters with the largest representation became the Lavender Lovers (24\%) and Blue Lovers (24\%). The Blue Lover segment was comprised mostly of former members of the Pink and White segments from the previous four-cluster analysis. They favored the whitemargin leaf, were very sensitive to price, and tended to have significantly lower-than-average purchase frequency, experience, and age. The Question Marks segment drew most of its members from the former Red segment, was least sensitive to price, and was significantly higher-than-average in age and proportion of male respondents.

As might be expected of a new or simulated product, many respondents expressed strong negative or positive feelings about the novelty of a blue geranium as manifested by an increase in the overall relative importance of flower color from $52 \%$ in the four-cluster (Table 1) to $60 \%$ in the six-cluster (Table 2). In the overall sample, the blue flower was the least-favored color, but the existence of a Blue Lover segment comprised of nearly a quarter of the respondents shows that potential demand for a blue geranium could be substantial. Furthermore, the profile of this segment indicated that they were not typical geranium buyers, and therefore they might generate an increase in total geranium sales. Finally, this study provided an effective evaluation of con- sumer reactions to a simulated plant product using digital-imaging technology, a method that may prove useful in testing other new or proposed products in the future.

\section{Literature Cited}

Gineo, W.M. 1990. A conjoint/logit analysis of nursery stock purchases. Northeastern J. Agr. and Resource Econ. 19:49-58.

Prince, T.L., J.L. Robertson, and L.H. Chatfield. 1980. Factors affecting the marketability of roses. J. Amer. Soc. Hort. Sci. 105:388-393.

Robertson, J.L. and L.H. Chatfield. 1982. Fresh flower merchandising in loose bunches. HortScience 17:593-595.

SAS Institute. 1998. ver. 6.12 for Win95. SAS Inst., Cary, N.C.

Shafer, B.S. and J.W. Kelly. 1986. The influence of cultivar, price, and longevity on consumer preferences for potted chrysanthemums. HortScience 21:1412-1413.

Townsley-Brascamp, W., N.E. Marr, E. Matsuo, and P.D. Relf. 1995. Evaluation and analysis of consumer preferences for outdoor ornamental plants. Acta Hort. 391:199-206. 